\title{
Güneş Takip Sistemlerinde Bulanık Mantık Kontrolü
}

\author{
Abdi Şenol $^{1}$, Orhan Ekren ${ }^{2 *}$, Savaş Şahin ${ }^{3}$ \\ ${ }^{1}$ Ege Üniversitesi, Güneş Enerjisi Enstitüsü, İzmir, Türkiye, (ORCID: 0000-0003-0119-871X), abdisenol@gmail.com \\ 2* Ege Üniversitesi, Güneş Enerjisi Enstitüsü, İzmir, Türkiye, (ORCID: 0000-0002-8670-7351), orhan.ekren @ ege.edu.tr \\ 3 İzmir Katip Çelebi Üniversitesi, Mühendislik ve Mimarlık Fakültesi, Elektrik-Elektronik Mühendisliği Bölümü, İzmir, Türkiye, (ORCID: 0000-0002-4165-3441), \\ sahin.savas@yahoo.com
}

(2nd International Conference on Access to Recent Advances in Engineering and Digitalization (ARACONF)-10-12 March 2021)

(DOI: $10.31590 /$ ejosat.900274)

ATIF/REFERENCE: Şenol, A., Ekren, O. \& Şahin, S. (2021). Güneş Takip Sistemlerinde Bulanık Mantık Kontrolü. Avrupa Bilim ve Teknoloji Dergisi, (24), 268-273.

$\ddot{O} z$

Güneş takip sistemleri, fotovoltaik panellere gelen güneş ışınlarının dik açı ile panele gelmesini sağlayan ve elektrik enerji üretim verimini arttıran sistemlerdir. Bu çalışmada, bir güneş takip sistemi akıllı kontrol algoritmalarından bulanık mantık ile tasarlanıp, deney düzeneği üzerinde ugulaması yapılmıştır. Deney düzeneğinde kullanılan mikrodenetleyicinin analog girişlerine bağlı dört ışık algılayıcısından alınan veriler, oluşturulan bulanık mantık kurallarına göre yorumlanır. Elde edilen kontrol işaretleri ile servo motorlar tasarlanan mekanik yapının çift eksende hareket etmesini sağlayarak, fotovoltaik panelin güneş 1şınlarını dik bir açı ile almasını sağlamıştır. Matlab/Simulink ortamında tasarlanan kontrolör gerçek sistemi kontrol etmiştir. Geliştirilen kontrol mekanizması sayesinde özellikle olumsuz hava koşullarında sistem bulunduğu konumu koruyabildiği için bu izleme yönteminin başarılı sonuçlar verdiği görülmektedir. Kullanılan bu akıllı kontrol ve güneş takip sistemi ile fotovoltaik sistemin elektrik üretme veriminde yaklaşık \%9 oranında verim artışı sağlanabildiği gözlenmiştir.

Anahtar Kelimeler: Güneş Takip, Gömülü Sistemler, Bulanık Mantık.

\section{Fuzzy Logic Control of Sun Tracking Systems}

\begin{abstract}
Sun tracking systems improve energy production efficiency and also provide direct solar radiation to the photovoltaic panels. In this study, a suntracking system has been controlled via fuzzy logic control as a smart control algorithm by using an experimental setup. In the setup, there is a microcontroller with four anolog input connected to light sensors and fuzzy algorithm. The resulted control signals drive the servo motors and tracks sun with two axes via Matlab/Simulink environment. In conclusion, the control system was able to keep the system very stabile position especially at bad weather conditions in a good success. As a result, the smart control and sun tracking system provide $9 \%$ improvement in photovoltaic energy production efficiency.
\end{abstract}

Keywords: Sun tracking, Embedded systems, Fuzzy logic.

\footnotetext{
* Sorumlu Yazar: Ege Üniversitesi, Güneş Enerjisi Enstitüsü, İzmir, Türkiye, ORCID: 0000-0002-8670-7351, orhan.ekren@ege.edu.tr
} 


\section{Giriş}

Bireylerin yaşam standartlarındaki değişim ve dünya nüfusundaki artışa bağlı olarak, enerjiye olan ihtiyaç her geçen gün giderek artmaktadır. Enerji ihtiyacını karşılamak için yaygın olarak kullanılan fosil kaynaklı rezervlerdeki sınırlı kapasite nedeniyle daha sürdürülebilir enerji kaynakları bulmak önümüzdeki yarım yüzyıl için önemli bir problem olarak görülmektedir. Diğer yandan fosil kaynaklı rezervlerin 2080 yılına kadar tükeneceği öngörülmektedir. (Banerjee et al., 2015).

Bilindiği üzere fosil kaynaklı yakıtların kullanılması sonucu açığa çıkan sera gazlarının meydana getirdiği sera etkisi, küresel 1sınmaya ve buna bağlı olarak da iklim değişikliklerine sebep olmaktadır. Bu küresel sorunu çözmek için, yenilenebilir enerji kaynaklarının, kullanımının artması gerekmektedir (de Paulo and Porto, 2018). Ençok bilinen ve kullanılan yenilenebilir enerji kaynağı olan Güneş, fotovoltaik paneller yardımıyla elektrik enerjisine ve kolektörler ile 1sıl enerjiye dönüştürülmektedir.

Fotovoltaik paneller, günün büyük bir bölümünde güneşi görebilecek bir biçimde çatı veya açık bir alana kurulmaktadırlar. Çünkü güneşten alınan verimin arttırılabilmesi için, fotovoltaik panel üzerine gelen güneş 1şınlarının dik bir açıda gelmesi gerekmektedir (Muhammad et al., 2019). Güneş hem yıl, hem de gün boyu hareket ettiği için, bir fotovoltaik panelin mümkün olan en yüksek gücü üretebilmesi, güneşin hareketini takip etmesiyle mümkün olabilmektedir. Mevsimsel olarak modüllerin yönü güneşe doğru ayarlanarak da panellerden alınan verim arttırılabilmektedir. $\mathrm{Bu}$ nedenle fotovoltaik panellerin elektrik enerjisi üretim verimini arttırmak için, maksimum güç noktası izleme veya güneş takip sistemleri gibi teknikler kullanılmaktadır. Sabit bir eğim açısıyla yerleştirilmiş fotovoltaik panele kıyasla, güneş takip sistemleri yaklaşık \%30 yakın elektrik üretiminde artış sağlarlar. $\mathrm{Bu}$ sistemlerin güneş takip açıları, yerleştirildikleri coğrafi bölgenin enlemine göre ve ilkim koşullarına bağlı olarak değişebilmektedir (Hafez et al., 2018).

Güneş takip sistemlerinin daha iyi çalışması ve verimliliği arttırmak için akıllı kontrol sistemlerinden faydalanılmaktadır (Nadia et al., 2018). Fuentes-Morales ve arkadaşları yaptıkları çalışmada güneş takip sistemlerine uygulanan kontrol algoritmalarını incelemişlerdir. Bulanık mantık kontrol algoritmasının, modern kontrol algoritmaları içerisinde $\% 10,53$ 'lük daha fazla tercih edilen yöntem olduğunu belirtmişlerdir (Fuentes-Morales et al., 2020).

Bilimsel yazında, araştırmacıların hem tek eksende hem de çift eksende güneş takibi yapabilen sistemlerle ilgili birçok çalışma yaptıkları görülmektedir. Göl ve Kıyak, bulanık mantık tabanlı çalışan ve tek eksende güneş takibi yapabilen bir sistemi, kontrol birimi olarak ATmega 328 mikrodenetleyisini kullanarak oluşturmuşlardır. Çalışma sonucunda, bulanık mantık tabanlı olmayan tek eksenli güneş takip sistemlerine kıyasla \%21,2 oranında bir enerji artışı gözlemlemişlerdir (Göl ve Kıyak, 2015). Zakariah ve arkadaşları, Arduino-Uno mikrodenetleyicisini ve 4 adet 1şı algılayıcısı kullanarak, çift eksenli güneş takip sistemini bulanık mantık ile tasarlamışlardır. Doğru akım motorları yardımıyla güneşe göre konumlanmasını sağladıkları güneş takip sisteminin, sabir bir açıda yerleştirimiş fotovoltaik panelden oluşan sisteme göre, panellerden alınan gücün veriminde $\% 18,13$ oranında bir iyileşme sağladığını gözlemlemişlerdir (Zakariah et al., 2015). Sinha ve Hui yaptıkları çalışmada, ışık algılayıcıları ve oransal-integral-türev
(PID) kontrolör kullanarak, çift eksende güneş takibi yapabilen bir sistem tasarlamışlardır. Oluşturdukları sistemin verimini arttırmak için PID kontrolörün kazanç değerlerini ayarlamak için, bulanık mantık kontrolörüni kullanmışlardır. Bu yöntemin, fotovoltaik panel güç üretimine ortalama \%29,76 oranında bir iyileştirme sağladığını gözlemlemişlerdir (Sinha and Hui, 2016). Alata ve arkadaşları, Matlab/Simulink programı yardımıyla tasarladıkları çift eksenli güneş takip sisteminde, modelleme ve kontrolör tasarımını Sugeno bulanık çıkarım sistemi kullanarak gerçekleştirmişlerdir. Bulanık kurallar ise, uyarlanabilir bir nörobulanık çıkarım sistemi (ANFIS) ile ayarlarlanmaktadır (Alata et al., 2005). Sendoya ve arkadaşları, bulanık mantık akıllı kontrol yöntemi ile çalışan, çift eksenli bir güneş takip sistemi tasarlamışlardır. Güneşin konumunu 4 adet ışı algılayıcısından alınan verilere bağlı olarak belirlemişlerdir. Fotovoltaik paneli güneşe göre konumlandırmak için mamdani bulanık çıkarım sisteminin kullanıldığı modelin çıkış gücünün, sabit açıdaki panellere kıyasla \%12,45 arttığını gözlemlemişlerdir (Sendoya et al., 2017).

$\mathrm{Bu}$ çalıșmada, akıllı kontrol yöntemlerinden biri olan bulanık mantık kullanarak, çift eksenli bir güneş takip sistemi geliştirilmesi amaçlanmıştır. Matlab/Simulink yazılımı, bulanık mantık kontrol sistemin kolay bir şekilde hazırlanıp, uygulanması ve çalışan sistemin takibinin kullanıcı ara yüzü ile yapılabilmesinden dolayı tercih edilmiştir. Arduino Uno mikrodenetleyicisinin analog girişlerine bağlı olan dört adet 1şı̆̆a duyarlı algılayıcıdan alınan voltaj değişimlerine bağlı olarak güneş takibi yapılmaktadır. Kullanılan fotovoltaik panel, bir platform üzerine yerleştirilmiş ve bu paltformun çift eksende hareketi servo motorlar kullanılarak gerçekleştirilmiştir. Çalışmada sabit 30o'lik bir açıda yerleştirilen bir fotovoltaik panel ile bulanık mantık kontrol sisteminin kullanıldığı güneş takip sistemiyle çalışan fotovoltaik panelin verimleri karş1laştırılmıştır.

\section{Materyal ve Metot}

Şekil 1'de şematik olarak gösterilen, bulanık mantık tabanlı çift eksenli güneş takip sistemi, 1,1W gücündeki bir fotovoltaik panel, panelin üzerine yerleştirilmiş 4 adet 1 şı algılayıcısı (LDR) ve çift eksende hareketi sağlayabilmek için 2 adet servo motordan oluşmaktadır.

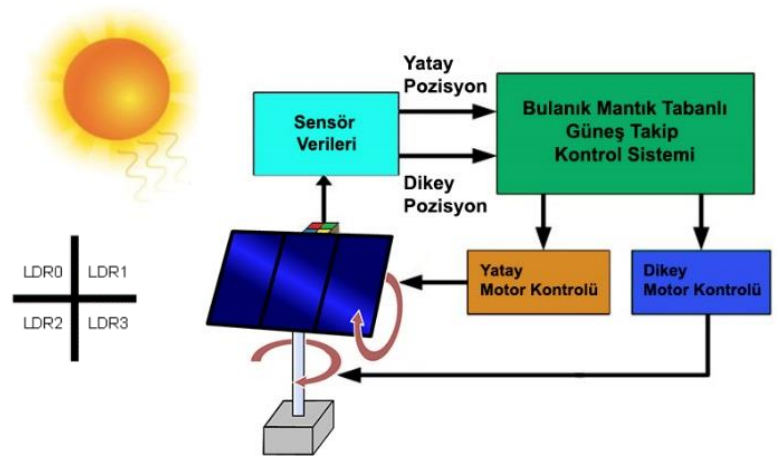

\section{Şekil 1. Güneş Takip Sisteminin Şematik Gösterimi}

Işık algılayıcılarından gölgelenme ve direkt 1şı alma durumlarına göre alınan farklı analog verileri mikrodenetleyici ile okunmaktadır. Tablo 1'de gösterildiği gibi bu değerler bulanık mantık kural tablolarında kullanılmak üzere -5 ile +5 arasındaki değerlere dönüştürülmektedir. Hem yatay eksende hem de dikey eksende hareketi sağlayan servo motorların girişlerine 0 ile 180 arasında değişen değerler uygulanarak, 
güneşe göre sistemin doğru bir açıda konumlanması sağlanmaktadır. Her bir servo motorun hareketi için iki adet giriş değişkeninden veri alınmaktadır.

Tablo 1. Giriş - Çıkış Değişken Aralık Değerleri

\begin{tabular}{lccc}
\hline \multicolumn{1}{c}{ Değişken } & Giriş-Çıkış & $\begin{array}{c}\text { Min. } \\
\text { Değeri }\end{array}$ & $\begin{array}{c}\text { Max. } \\
\text { Değeri }\end{array}$ \\
\hline $\boldsymbol{e}$ (hata) & Giriş & -5 & +5 \\
\hline $\begin{array}{l}\text { de (hatanın } \\
\text { değişimi) }\end{array}$ & Giriş & -5 & +5 \\
\hline $\begin{array}{l}\text { Motor Konumu } \\
\text { (dönme açısı) }\end{array}$ & Çıkış & 0 & 180 \\
\hline
\end{tabular}

\subsection{Bulanık Mantık}

Tasarlanan sistem için Matlab yazılımında yer alan Bulanık Mantık araç kutusu kullanılmıştır (Fuzzy Logic Toolbox, 2021). Işık algılayıcılarından alınan veriler ve çıkış değişkenleri için üçgen üyelik fonksiyonu kullanılmıştır. Yatay eksende hareketi sağlayan için LDR0 ile LDR2 üzerinden alınan değerlerin ortalamas1 $\left(\mathrm{V}_{\mathrm{SOL}}\right)$ ile LDR1 ve LDR3 üzerinden alınan değerlerin ortalaması $\left(\mathrm{V}_{\mathrm{SAG}}\right)$ arasındaki gerilim farklılıkları kullanılmaktadır (Şekil 1). Burada fark $e_{1}$ (hata) ve de $e_{1}$ (hatanın değişimi) olarak gösterilir. Dikeyde hareketi sağlamak için ise LDR0 ile LDR1 üzerinden alınan değerlerin ortalamas1 ( $\left.\mathrm{V}_{\mathrm{UST}}\right)$ ile LDR2 ve LDR3 üzerinden alınan değerlerin ortalamas1 $\left(\mathrm{V}_{\mathrm{ALT}}\right)$ arasındaki gerilim farklılıkları kullanılmaktadır. Burada fark $e_{2}$ ve $d e_{2}$ olarak ifade edilir. $e$ ve de girişleri ile motor konumu olarak adlandırılan çıkış değişkeni için belirlenen değer aralıkları Tablo 2'de verilmişstir.

Tablo 2. Giriş - Çıkış Değişken Aralık Değerlerinin Dilsel Ifadeleri

\begin{tabular}{|c|c|c|c|}
\hline & $e$ & $d e$ & $\begin{array}{c}\text { Motor } \\
\text { konumu }\left(^{\circ}\right)\end{array}$ \\
\hline $\begin{array}{c}\text { Negatif } \\
\text { Büyük }(N B)\end{array}$ & $(-5)-(-3,5)$ & $(-5)-(-3,5)$ & $0-40$ \\
\hline $\begin{array}{c}\text { Negatif Orta } \\
(N O)\end{array}$ & $(-5)-(-1,5)$ & $(-5)-(-1,5)$ & $0-70$ \\
\hline $\begin{array}{c}\text { Negatif } \\
\text { Küçük (NK) }\end{array}$ & $(-3,5)-0$ & $(-3,5)-0$ & $40-90$ \\
\hline $\begin{array}{c}\text { Yaklaşık Sıfir } \\
\text { (YS) }\end{array}$ & $(-1,5)-1,5$ & $(-1,5)-1,5$ & $70-110$ \\
\hline $\begin{array}{c}\text { Pozitif Küçük } \\
(\text { PK) }\end{array}$ & $0-3,5$ & $0-3,5$ & $90-140$ \\
\hline $\begin{array}{c}\text { Pozitif Orta } \\
(\text { PO })\end{array}$ & $1,5-5$ & $1,5-5$ & $110-180$ \\
\hline $\begin{array}{c}\text { Pozitif Büyük } \\
(\text { PB })\end{array}$ & $3,5-5$ & $3,5-5$ & $140-180$ \\
\hline
\end{tabular}

Kural tablosu için 7 farklı giriş seviyesi tanımlanmıştır. Giriş değişkenleri; Negatif Büyük (NB), Negatif Orta (NO), Negatif Küçük (NK), Yaklaşık Sıfir (YS), Pozitif Küçük (PK), Pozitif Orta (PO) ve Pozitif Büyük (PB) olarak tanımlanan bulanık kümeler halinde Şekil 2'deki gibi gösterilmektedir. Giriş üyelik fonksiyonları her iki giriş için aynı belirlenmiştir.
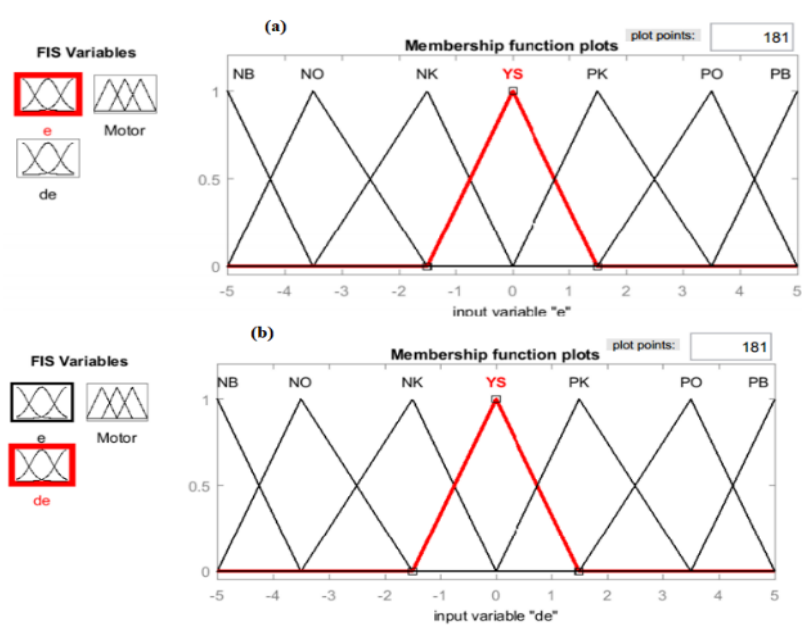

Şekil 2. Giriş Üyelik Fonksiyonları a) e Giriş Üyelik Fonksiyonu b) de Giriş Üyelik Fonksiyonu

Bulanık mantık denetleyici çıkışında ise servo motor konum açı değeri 0 ile $180^{\circ}$ arasında üretilerek, bu değerler aralığında servo motorların fotovoltaik paneli güneşi takip etmesi sağlanır. Çıkış üyelik fonksiyonları her iki çıkış için aynı belirlenmiştir. Güneş takip sisteminin çift eksende hareketini sağlayan kural tablosu Tablo 3 'te verilmiştir.

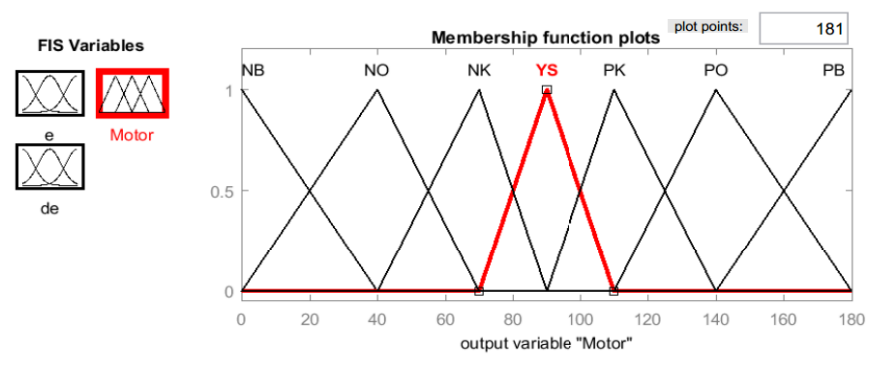

Şekil 3. Çıkış Üyelik Fonksiyonu

Tablo 3. Bulanık Mantık Kural Tablosu

\begin{tabular}{cccccccc}
\hline e/de & NB & NO & NK & YS & PK & PO & PB \\
\hline NB & NB & NB & NB & NB & NO & NK & YS \\
\hline NO & NB & NB & NO & NO & NK & YS & PK \\
\hline NK & NB & NO & NK & NK & YS & PK & PO \\
\hline YS & NB & NO & NK & YS & PK & PO & PB \\
\hline PK & NO & NK & YS & PK & PK & PO & PB \\
\hline PO & NK & YS & PK & PO & PO & PB & PB \\
\hline PB & YS & PK & PO & PB & PB & PB & PB
\end{tabular}

Bulanıklaştırma işlemi sonucu oluşan bulanık veriler, kural tablosuna göre işlendikten elde edilen sonuçlar, Mamdani çıkarımı kullanılarak yordamlanır. Mamdani çıkarımları Şekil 4'te Matlab-Bulanık Mantık araç kutusunda kuralların yazıldığ pencere verilmiştir. Son aşamada, durulaştırma işlemi olarak da alan merkezi veya alan ağırlık merkezi yöntemi kullanılmıştır. 


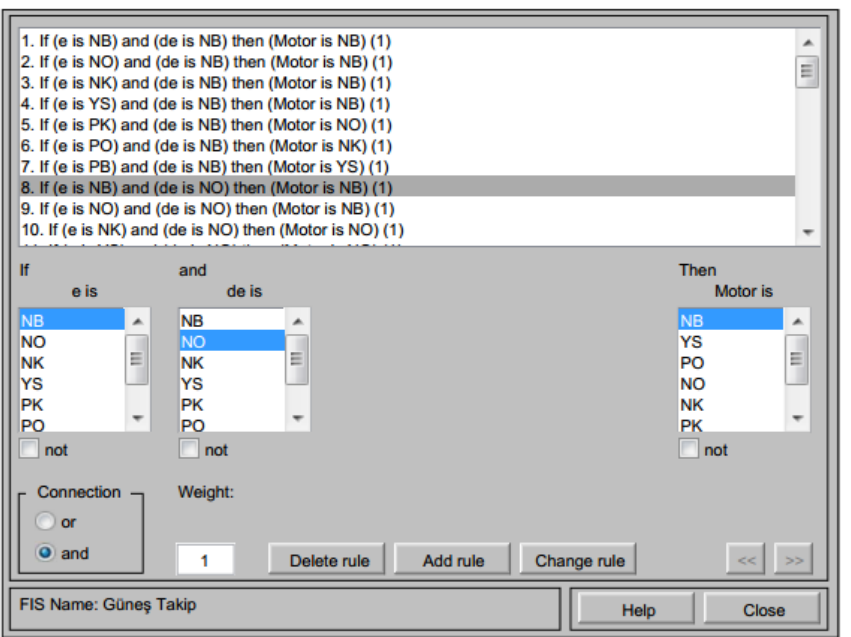

Şekil 4. Çıkarım Tablosunun Oluşturulması

$\mathrm{Bu}$ çalışma kapsamında geliştirilen bulanık mantık tabanlı çift eksenli güneş takip sistemi akış diyagramı Şekil 5 'te gösterilmektedir.

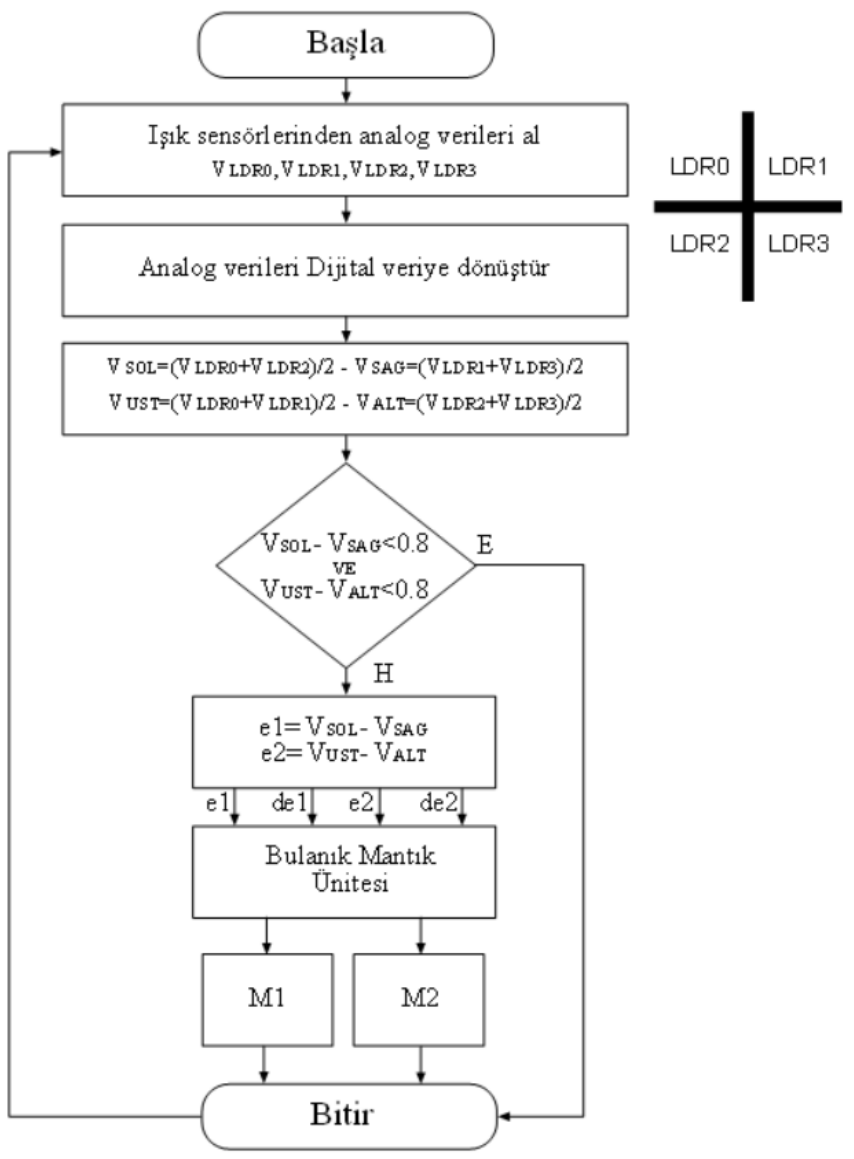

Şekil 5. Bulanık Mantık Tabanlı Güneş Takip Sisteminin Akış Diyagramı

\subsection{Simulink ve Mikrodenetleyici Tasarımı}

Simulink ve ATMEGA işlemciye sahip mikrodenetleyici haberleşmesi Arduino kütüphane ile yapılmıştır (Mathworks, 2021). Sistem haberleşmesi USB portu üzerinden sağlanmıştır (Şekil 6). Real Time Pacer bloğu, iki ortam arasındaki senkronizasyonu için kullanılmıştır.

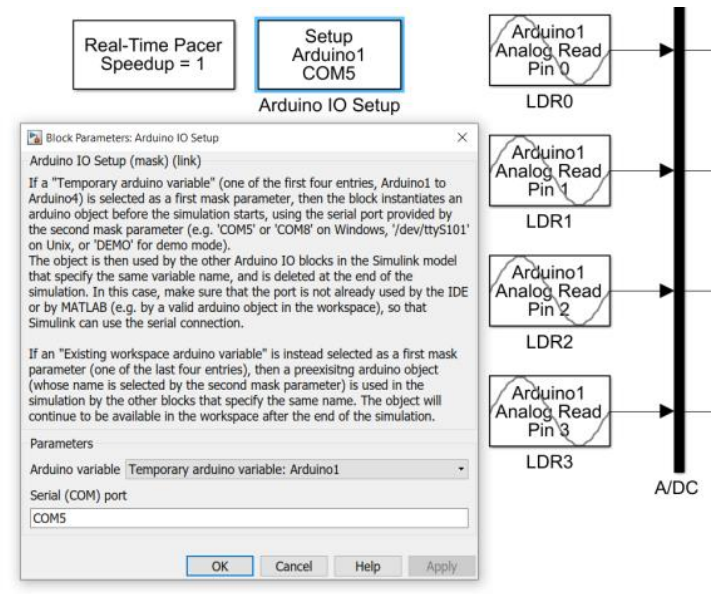

Şekil 6. Matlab/Simulink - Arduino Haberleşmesi ve Analog Girişlerin Okunması

Yatay eksende güneş takibi için, sol ve sağ 1 şı algılayıcılarından okunan veriler arasında oluşan farka göre yatay servo motorun bulanık mantık kural tablosuna göre hareket etmektedir. Dikey eksendeki hareket için ise alt ve üst 1şık algılayıcılarından okunan veriler arasında oluşan farka göre dikey servo motorun bulanık mantık kural tablosuna göre hareket etmesi sağlanmıştır. Bu yapı için oluşturulan bloklar Şekil 7'de gösterilmektedir.

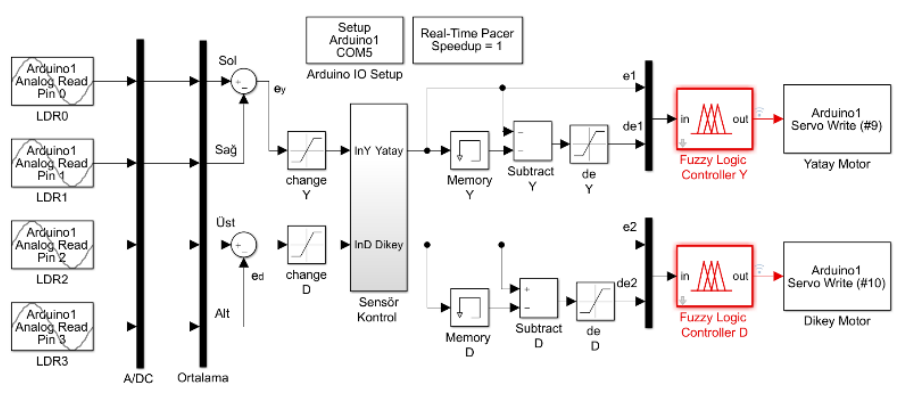

Şekil 7. Güneş Takip Sistemi Matlab/Simulink Blokları

\section{Araştırma Sonuçları ve Tartışma}

$\mathrm{Bu}$ çalışmada tasarlanan prototip Şekil 8'de gösterilmektedir. $30^{\circ}$ sabit bir açıda güney yönüne bakan fotovoltaik panel ile çift eksende güneş takibi yapan sistem üzeine yerleştirilen fotovoltaik panelin ürettikleri anlık gerilim farklılıkları hesaplanarak birbirleriyle kıyaslanmıştır. Elde edilen bir günlük veriler iki farklı zaman dilimi için Şekil 9'daki gibi elde edilmiştir. 


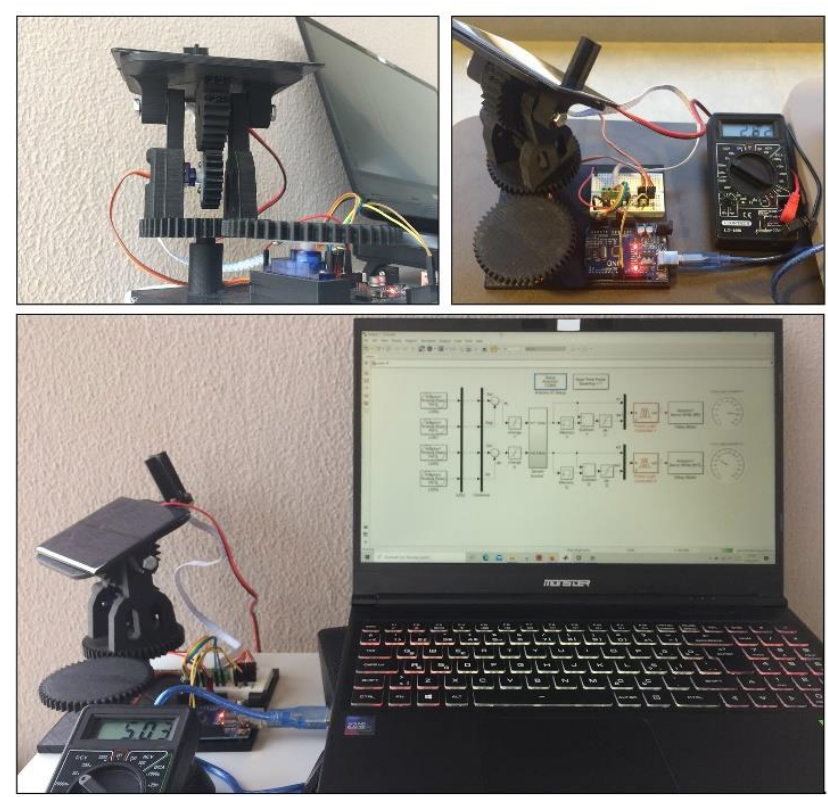

Şekil 8. Güneş Takip Sistemi Prototipi
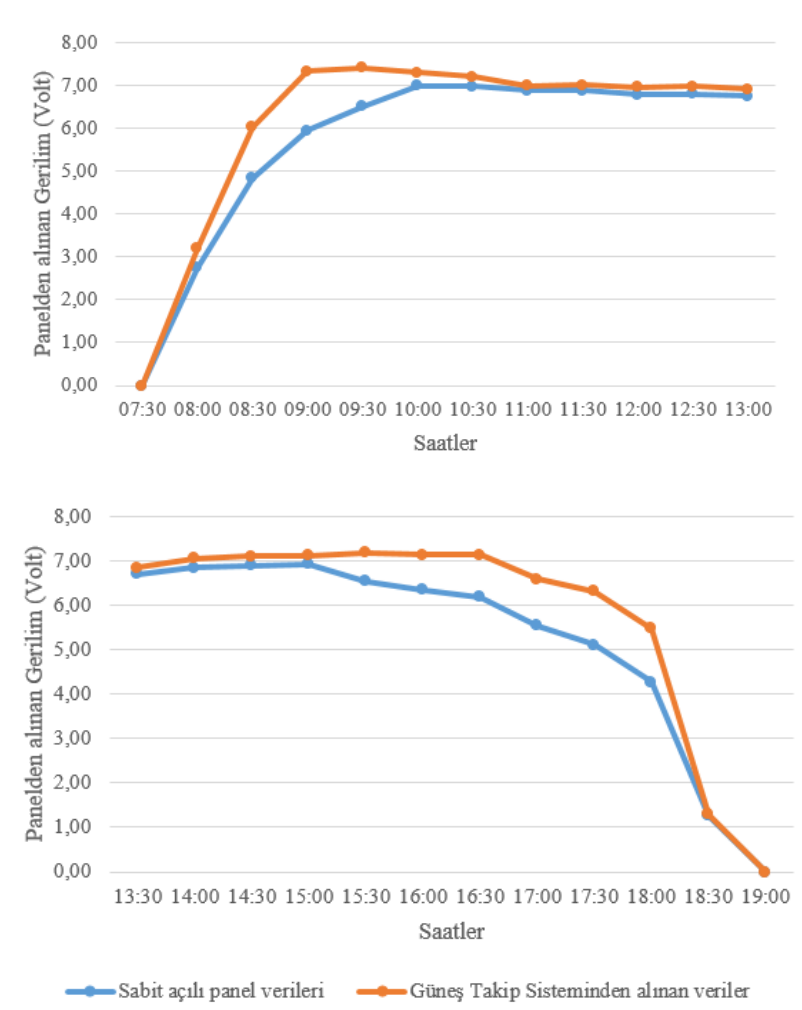

Şekil 9. 07:30 - 13:00 ve 13:30 - 19:00 Saatleri Arası Ölçülen Çıkış Verileri

Elde edilen verilere göre yatay ve dikey hareketler için geliştirilen bulanık mantık tabanlı algoritma için fotovoltaik panelin uygun bir biçimde güneşe göre konumlanması sağlanmış. Çalışmada özellikle sabah ve akşam saatlerinde güneş takip sisteminin verimin daha yüksek olduğu gözlemlenmiştir.

\section{Sonuç}

$\mathrm{Bu}$ çalışmada, bulanık mantık kullanılarak, fotovoltaik güneş panellerinin doğu-batı ve kuzey-güney yönlerinde güneşi izlemesi amaçlanmıştır. Belirlenen saha içerisinde güney yönüne $30^{\circ}$ 'lik sabit bir açıyla yerleştirilmiş fotovoltaik panel ile güneş takip kullanılan bir panelden anlık olarak elde edilen gerilim değerleri incelenmiştir. Prototipi hazırlanan güneş takip sisteminin çalışması ve izlenmesi sırasında Matlab/Simulink programı kullanılmıştır. Mikrodenetleyici girişlerine uygulanan 1şık verilerine göre, bulanık mantık tablolarını kullanarak, çıkışında yer alan servo motorlara yön vermektedir. Prototip sistem; düşük maliyetli, izleme konusunda başarılı sonuçlar veren, kolay uygulanabilir ve geliştirilebilir bir yapıya sahiptir. Geliştirilen kontrol mekanizması sayesinde özellikle olumsuz hava koşullarında sistem bulunduğu konumu koruyabildiği için bu izleme yönteminin başarılı sonuçlar verdiği görülmektedir. Kullanılan bu akıllı kontrol ve güneş takip sistemi ile fotovoltaik sistemin elektrik üretme veriminde yaklaşık \%9 oranında verim artışı sağlanabildiği gözlenmiştir.

\section{Kaynakça}

Alata, M., Al-Nimr, M. A., \& Qaroush, Y. (2005). Developing a multipurpose sun tracking system using fuzzy control. Energy Conversion and Management, 46(7-8), 1229-1245.

Banerjee A., Majumder A., Banerjee A., Sarkar S., and Bosu D. (2015), "Harnessing non conventional solar energy through conventional thermal power systems," International Conference and Workshop on Computing and Communication, pp. 1-7

de Paulo, A. F., \& Porto, G. S. (2018). Evolution of collaborative networks of solar energy applied technologies. Journal of Cleaner Production, 204, 310-320.

Fuentes-Morales, R. F., Diaz-Ponce, A., Peña-Cruz, M. I., Rodrigo, P. M., Valentín-Coronado, L. M., Martell-Chavez, F., \& Pineda-Arellano, C. A. (2020). Control algorithms applied to active solar tracking systems: A review. Solar Energy, 212, 203-219.

Fuzzy Logic Toolbox, "Fuzzy Logic Toolbox", https://ww2.mathworks.cn/en/products/fuzzy-logic.html (Erişim Tarihi: 16 Şubat 2021)

Göl, G. ve Kıyak, E. (2015). Bulanık Mantık Tabanlı Tek Eksen Güneş Takip Sisteminin Tasarımı Ve Uygulaması, Atatürk Üniversitesi 2. Ulusal Yönetim Bilişim Sistemleri Kongresi, Erzurum,10s.

Hafez, A. Z., Yousef, A. M., \& Harag, N. M. (2018). Solar tracking systems: Technologies and trackers drive types-A review. Renewable and Sustainable Energy Reviews, 91, 754-782.

Mathworks, "Simulink Support Package for Arduino Hardware", https://ww2.mathworks.cn/matlabcentral/fileexchange/4031 2-simulink-support-package-for-arduino-hardware (Erişim Tarihi: 16 Şubat 2021)

Muhammad, J. Y. U., Jimoh, M. T., Kyari, I. B., Gele, M. A., \& Musa, I. (2019). A review on solar tracking system: A technique of solar power output enhancement. Engineering Science, 4(1), 1-11.

Nadia, A. R., Isa, N. A. M., \& Desa, M. K. M. (2018). Advances in solar photovoltaic tracking systems: A review. Renewable and sustainable energy reviews, 82, 2548-2569.

Sendoya, D, Murcia, D.F. \& García, S.O. (2017). Design and implementation of a photovoltaic solar tracker using fuzzy 
control for Surcolombiana University. ARPN Journal of Engineering and Applied Sciences. 12. 2271-2276.

Sinha, D. and Hui, N.B. (2016). Fuzzy Logic-based Dual Axis Solar Tracking System, International Journal of Computer Applications, 155(12):13-18p

Suganthi, L., Iniyan, S., \& Samuel, A. A. (2015). Applications of fuzzy logic in renewable energy systems-a review. Renewable and sustainable energy reviews, 48, 585-607.

Şenol, A., 2021, Fotovoltaik Paneller İçin Çift Eksenli Güneş Takip Sisteminde Bulanık Mantık Kontrolü, Yüksek Lisans Tezi, Ege Üniversitesi Fen Bilimleri Enstitüsü, 91s.

Zakariah, A., Jamian, J. J., \& Yunus, M. A. M. (2015). Dual-axis solar tracking system based on fuzzy logic control and Light Dependent Resistors as feedback path elements. In 2015 IEEE Student Conference on Research and Development (SCOReD) (pp. 139-144). IEEE. 